\title{
Phencyclidine Increases Forebrain Monoamine Metabolism in Rats and Monkeys: Modulation by the Isomers of HA966
}

\author{
J. David Jentsch, ${ }^{1}$ John D. Elsworth,, ${ }^{2,3}$ D. Eugene Redmond Jr., ${ }^{2,4}$ and Robert H. Roth ${ }^{2,3}$ \\ Departments of ${ }^{1}$ Neurobiology, ${ }^{2}$ Psychiatry, ${ }^{3}$ Pharmacology, and ${ }^{4}$ Neurosurgery, Yale University School of Medicine, \\ New Haven, Connecticut 06510
}

\begin{abstract}
The noncompetitive NMDA receptor antagonist phencyclidine (PCP) has psychotomimetic properties in humans and activates the frontal cortical dopamine innervation in rats, findings that have contributed to a hyperdopaminergic hypothesis of schizophrenia. In the present studies, the effects of the enantiomers of 3-amino-1-hydroxypyrrolid-2-one (HA966) on PCP-induced changes in monoamine metabolism in the forebrain of rats and monkeys were examined, because HA966 has been shown previously to attenuate stress- or drug-induced activation of dopamine systems. In rats, PCP (10 mg/kg, i.p.) potently activated dopamine (DA) turnover in the medial prefrontal cortex (PFC) and nucleus accumbens. Serotonin utilization was also increased in PFC. Pretreatment with either R-(+)HA966 (15 $\mathrm{mg} / \mathrm{kg}$, i.p.) or S-(-)HA966 (3 $\mathrm{mg} / \mathrm{kg}$, i.p.) partially blocked PCP-induced increases in PFC DA turnover, whereas neither
\end{abstract}

enantiomer altered the effect of PCP on DA turnover in the nucleus accumbens or the PCP-induced increases in serotonin turnover in PFC. PCP (0.3 mg/kg, i.m.) exerted regionally selective effects on the dopaminergic and serotonergic innervation of the monkey frontal cortex, effects blocked by pretreatment with S-(-)HA966 (3 mg/kg, i.m.). Importantly, these data demonstrate that in the primate, PCP has potent effects on dopamine transmission in the frontal cortex, a brain region thought to be dysfunctional in schizophrenia. In addition, a role for S-(-)HA966 as a modulator of cortical monoamine transmission in primates is posited.

Key words: dopamine; HA966; monkey; phencyclidine; prefrontal cortex; psychotomimetic; rat; schizophrenia; serotonin; turnover
The dopaminergic innervation of the prefrontal cortex (PFC) is highly responsive to stress and psychomotor stimulants (Deutch and Roth, 1990; Horger and Roth, 1995; Roth and Elsworth, 1995). Mild stress selectively increases dopamine (DA) turnover and release in the PFC (Thierry et al., 1976). Likewise, psychomotor stimulants such as amphetamine (During et al., 1987), cocaine (Sorg and Kalivas, 1993), opiates (Kim et al., 1986), $\Delta 9$ tetrahydrocannabinol (Bowers and Morton, 1994; Jentsch et al., 1997), and noncompetitive antagonists of the NMDA receptor such as phencyclidine (PCP) increase the release and turnover of DA in the PFC and nucleus accumbens (NAc). Serotonin (5-HT) and norepinephrine utilization are also increased in these areas by PCP (Deutch et al., 1987; Bowers and Morton, 1994; Hondo et al., 1994).

PCP has profound psychotomimetic effects in normal humans (Luby et al., 1959; Javitt and Zukin, 1991) and can precipitate psychotic episodes in schizophrenic subjects (Ital et al., 1967; Javitt and Zukin, 1991). PCP-induced dysregulation of the mesocortical DA innervation may be relevant to these schizophreniform effects, because dopaminergic dysfunction in the PFC has been hypothesized in schizophrenia (Robbins, 1990; Grace, 1991; Deutch, 1992). As such, pharmacological manipulation of the

\footnotetext{
Received Oct. 11, 1996; revised Dec. 5, 1996; accepted Dec. 9, 1996.

This work was supported in part by U.S. Public Health Service Grants MH-14092 (R.H.R.) and MH-00643 (D.E.R.), the Scottish Rite Schizophrenia Research Program, N.M.J., U.S.A. (J.D.J.), and the Axion Research Foundation. We thank Mark Brittan, Yufang Pan, and the staff of the St. Kitts Biomedical Research Foundation for their expert technical assistance.

Correspondence should be addressed to Dr. Robert H. Roth, Department of Pharmacology, Yale University School of Medicine, P.O. Box 208066, New Haven, CT 06520-8066.

Copyright (C) 1997 Society for Neuroscience 0270-6474/97/171769-07\$05.00/0
}

effects of PCP on mesocortical DA systems may be relevant to the treatment of PCP psychosis and schizophrenia.

The effects of mild stress on frontal cortical DA transmission can be blocked by anxiolytic benzodiazepine (BZ) agonists (Fadda et al., 1978; Lavielle et al., 1978; Reinhard et al., 1982) and, as with mild stress, the effects of PCP on mesotelencephalic DA neurons can be blocked by diazepam (Bowers and Hoffman, 1989; Bowers and Morton, 1992), suggesting that the PCP-induced mesoprefrontal DA response may be sensitive to modulation as is the PFC DA increase evoked by mild stress.

Investigations in this lab have shown that like BZ agonists, 3-amino-1-hydroxypyrrolid-2-one (HA966) can modulate the mesotelencephalic DA systems. R- $(+)$ HA966, a strychnineinsensitive glycine site partial agonist/functional NMDA receptor antagonist, can block increases in PFC but not NAc DA turnover induced by restraint stress (Morrow et al., 1993), conditioned fear (Goldstein et al., 1994), and the BZ receptor inverse agonist FG7142 (Horger et al., 1996; Murphy et al., 1996c). Similarly, S- $(-)$ HA966, a $\gamma$-butyrolactone-like substance (Singh et al., 1990), potentially acting at $\mathrm{GABA}_{\mathrm{B}}$ or $\gamma$-hydroxybutyrate receptors, prevents increases in PFC DA utilization induced by restraint stress, conditioned fear (Morrow et al., 1995), and FG7142 (Murphy et al., 1996c). Finally, we have recently shown that both enantiomers of HA966 can prevent the increases in PFC DA turnover induced by $\Delta$ 9-tetrahydrocannabinol (Jentsch et al., 1997). S-(-)-HA966 appears to be approximately 5 to 10 times more potent than R-(+)-HA966 in reducing hyperdopaminergic states induced by stress, FG7142, or $\Delta 9$-tetrahydrocannabinol.

In the present study, we examined the effects of both $\mathrm{R}-(+)-$ and S- $(-)$ HA966 on phencyclidine-induced changes in DA and 5-HT turnover in the PFC, NAc, and striatum (STR) of rats. In 


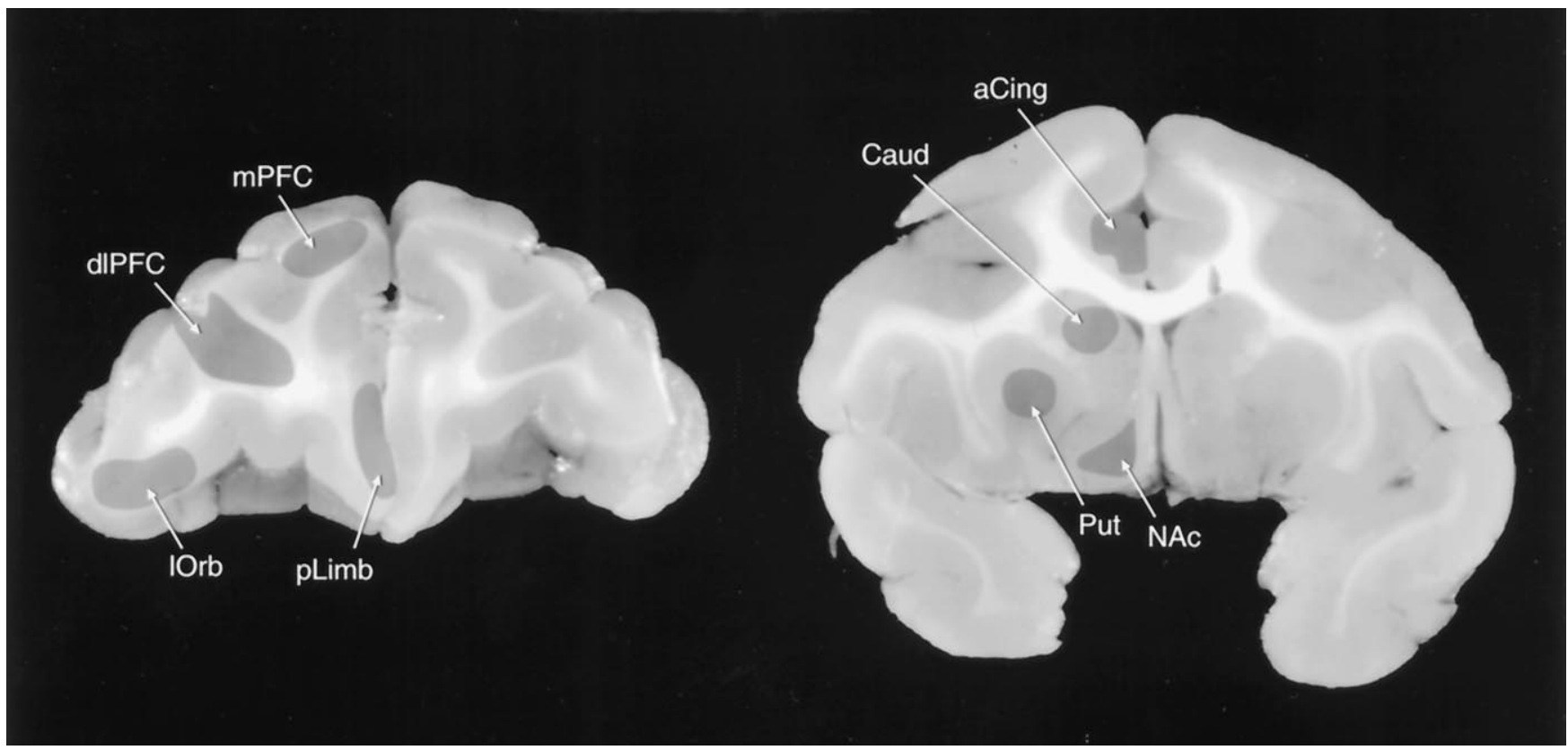

Figure 1. Regional dissections of African Green monkey brain. dlPFC, Dorsolateral PFC; mPFC, medial PFC; lOrb, lateral orbital cortex; $p L i m b$, prelimbic cortex; aCing, anterior cingulate cortex; NAc, nucleus accumbens; Caud, caudate nucleus; Put, putamen.

particular, we investigated the effects of doses of each enantiomer that when given alone, had no significant effect on basal DA levels or turnover. In addition, we extended these findings to the monkey brain to examine whether the effects of PCP and S- $(-)$ HA966 are conserved in the primate brain, the more extensive and intricate mesoprefrontal DA system of which is more relevant to human neurobiology. Our findings indicate that acute PCP administration markedly activates DA turnover in the PFC of rats and monkeys and that this increase is attenuated by pretreatment S- $(-)$ HA966 in both species.

Portions of this work have been presented in abstract form.

\section{MATERIALS AND METHODS}

Animals. Forty male Sprague Dawley CAMM rats (Charles River Labs, Portage, MI) and 10 young adult male African green monkeys (Cercopithecus sabaeus aethiops) of the St. Kitts Biomedical Research Facility (St. Kitts, West Indies) were used as subjects. All subjects were maintained under conditions consistent with USDA standards and the National Institutes of Health "Guide for the Care and Use of Laboratory Animals." In addition, all protocols were approved by the appropriate institutional animal care and use committees.

The rats were maintained on a $12 \mathrm{hr}$ light/dark cycle, with the light phase being 7:00 A.M. to 7:00 P.M. Food and water was provided ad libitum. St. Kitts monkeys were housed individually in standard primate squeeze cages in an open but covered facility under daylight conditions. Monkeys were fed monkey chow and fruit supplements and had water available ad libitum.

Drugs. Phencyclidine hydrochloride (Research Biochemicals, Natick, MA) was administered at a dose of $10 \mathrm{mg} / \mathrm{kg}$ (rats) or $0.3 \mathrm{mg} / \mathrm{kg}$ (monkeys) in sterile saline. Both enantiomers of HA966 were provided through the National Institute of Mental Health Synthesis Program (courtesy of Research Biochemicals). R-(+)HA966 (15 mg/kg) and S- $(-)$ HA966 (3 $\mathrm{mg} / \mathrm{kg}$ ) were delivered in saline $15 \mathrm{~min}$ before PCP administration. Al injections were given at a volume of $1 \mathrm{ml} / \mathrm{kg}$ intraperitoneally (rats) or 0.1 $\mathrm{ml} / \mathrm{kg}$ intramuscularly (monkeys). In all cases, vehicle treatments represented an injection of an equivalent volume of sterile saline.

Biochemistry. All rats weighed 250-275 gm at the time of death. Killing was performed during the animals' light phase. Rats were killed by rapid decapitation $1 \mathrm{hr}$ after PCP administration. The brains were quickly removed, and brain regions were dissected out on a thermostatically chilled platform. Samples were immediately frozen on dry ice and stored at $-70^{\circ} \mathrm{C}$ until assayed.
Monkeys, weighing $2.0-4.0 \mathrm{~kg}$ at the time of death, were anesthetized with an overdose of sodium pentobarbital $(75 \mathrm{mg} / \mathrm{kg}) 1 \mathrm{hr}$ after PCP administration. At the loss of corneal reflex, the subjects were perfused transcardially with ice-cold heparinized saline until the effluent ran clear. The brain was removed, sliced in $4 \mathrm{~mm}$ coronal sections, and regionally dissected on a thermostatically controlled platform according to Figure 1. Tissues were frozen immediately in liquid nitrogen and then stored at $-70^{\circ} \mathrm{C}$ until assay.

Tissues were prepared with dihydroxybenzylamine as an internal standard for catechols and $N$-methyl 5-HT as an internal standard for the indoles. Samples were homogenized in $400 \mu$ l of ice-cold $0.1 \mathrm{M}$ perchloric acid and centrifuged at $17600 \times g$, and the supernate was analyzed directly with HPLC using electrochemical detection with a glassy carbon electrode at $+0.7 \mathrm{~V}$ (BAS, West Lafayette, IN) and a reversed-phase column (3 $\mu \mathrm{m} \mathrm{C18}$ beads, $100 \AA$ diameter, $10 \mathrm{~cm}$ length; BAS, West Lafayette, IN). Pellets were analyzed for protein content according to Lowry et al. (1951).

Mobile phase used for HPLC was an $8 \%$ solution of acetonitrile containing $0.6 \%$ tetrahydrofuran, $0.1 \%$ diethylamine, $0.025 \mathrm{~mm}$ EDTA, $2.3 \mathrm{~mm}$ 1-octane-sulfonic acid, $30 \mathrm{~mm}$ sodium citrate, and $13.7 \mathrm{~mm}$ sodium dihydrogen phosphate, final $\mathrm{pH} 3.1$.

Measurements of turnover were made as the ratio of tissue concentration (in nanograms per milligram protein) of the primary metabolite DOPAC, homovanillic acid, or 5-hydroxyindoleacetic acid to the parent amine (DA and 5-HT).

Statistics. Statistical analysis was performed on a Macintosh IIcx running Statview II (Abacus Concepts, Berkeley, CA). ANOVA and unpaired Student's $t$ test were used where appropriate. A $p$ value $<0.05$ was considered significant.

\section{RESULTS}

\section{PCP stimulates monoamine utilization in rodent and primate brain}

PCP $(10 \mathrm{mg} / \mathrm{kg}$, i.p.) significantly increased turnover of DA in the $\operatorname{PFC}(T=-6.15 ; \mathrm{df}=14 ; p<0.001)$ and NAc $(T=-7.47 ; \mathrm{df}=$ $15 ; p<0.001$ ) of rats $1 \mathrm{hr}$ after administration (Fig. 2). This alteration in DA turnover is indicative of changes in DOPAC levels, because no significant alteration in DA concentrations was noted after PCP administration (Table 1). Likewise, 5-HT turnover was increased after PCP administration in the PFC (Fig. 3) and STR (Fig. 3); 5-HT turnover was not measured in the NAc. Similarly, PCP (0.3 mg/kg, i.m.) significantly increased DA 


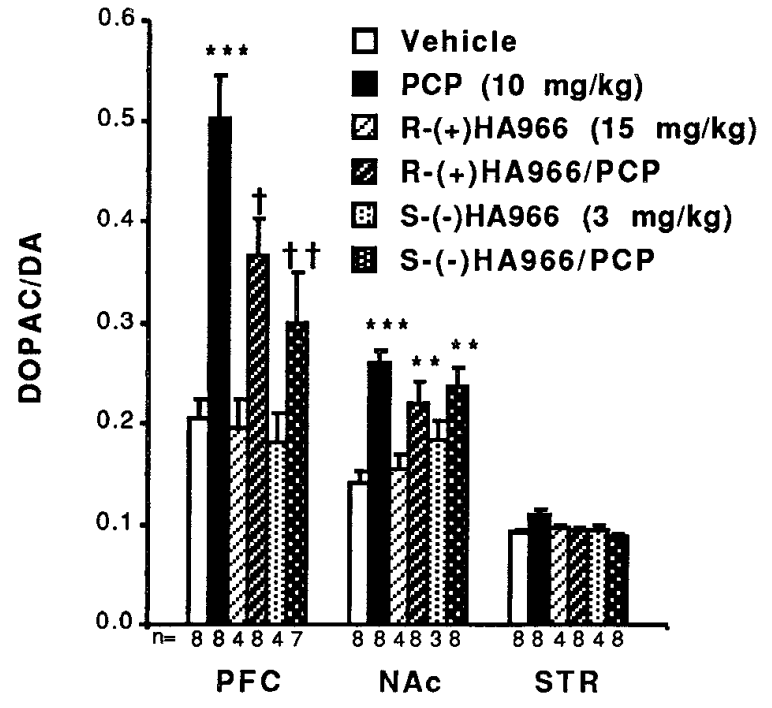

Figure 2. PCP significantly increases DA turnover in the PFC and NAc of the rat. The effect of PCP on PFC DA metabolism is partially blocked by $\mathrm{R}-(+)-$ or S- $(-)$ HA966, whereas neither enantiomer is able to block PCP-induced activation of NAc DA utilization. Results are expressed as mean \pm SEM. Significantly increased relative to vehicle: ${ }^{* * *} p<0.001$, ${ }^{* *} p<0.01$; ${ }^{\dagger}$ significantly reduced relative to PCP: $p<0.05 ;{ }^{\dagger \dagger}$ significantly reduced relative to PCP: $p<0.01$.

Table 1. Absolute dopamine levels are unaltered in rat brain by PCP or HA966

\begin{tabular}{lcc} 
PFC & Saline & PCP $(10 \mathrm{mg} / \mathrm{kg})$ \\
Saline & $1.47 \pm 0.25$ & $1.21 \pm 0.18$ \\
R- $(+) H A 966(15 \mathrm{mg} / \mathrm{kg})$ & $1.18 \pm 0.22$ & $1.40 \pm 0.16$ \\
S- $(-) H A 966(3 \mathrm{mg} / \mathrm{kg})$ & $1.06 \pm 0.23$ & $1.12 \pm 0.16$ \\
NAc & & \\
Saline & $89.98 \pm 22.66$ & $37.42 \pm 7.00$ \\
R- $(+) H A 966(15 \mathrm{mg} / \mathrm{kg})$ & $55.24 \pm 22.51$ & $46.44 \pm 19.55$ \\
S- $(-)$ HA966 $(3 \mathrm{mg} / \mathrm{kg})$ & $83.28 \pm 5.72$ & $46.56 \pm 13.38$ \\
STR & & \\
Saline & $191.67 \pm 13.12$ & $211.04 \pm 18.58$ \\
R- $(+) H A 966(15 \mathrm{mg} / \mathrm{kg})$ & $185.62 \pm 23.64$ & $220.48 \pm 14.48$ \\
S- $(-)$ HA966 $(3 \mathrm{mg} / \mathrm{kg})$ & $234.96 \pm 7.96$ & $218.12 \pm 5.52$ \\
\hline
\end{tabular}

Neither phencyclidine nor HA966 significantly alters DA concentrations in rat brain, indicating that all drug effects on DA turnover are dependent on changes in DOPAC concentrations. Results are expressed as mean DA concentration in $\mathrm{ng} / \mathrm{mg}$ protein \pm SEM.

turnover, without significantly altering DA concentrations (Table 2), in several regions of the primate frontal cortex (Fig. 4). Significant increases in DA metabolism after PCP administration were observed in the dorsolateral PFC (Walker's area 46: $T=$ -2.35 ; df $=8 ; p=0.047$ ); medial PFC (Brodmann's area 9: $T=$ $-2.53 ; \mathrm{df}=9 ; p=0.032)$; lateral orbital cortex (Brodmann's area 12: $T=-6.47$; df $=4 ; p=0.003$ ); and prelimbic cortex (Brodmann's area 33 and adjacent ventral cortex: $T=-4.64$; df $=2$; $p=0.043$ ). In contrast, there was no significant activation of DA utilization in the anterior cingulate cortex (Brodmann's area 24) or in any subcortical area studied (Fig. 4) including the NAc, caudate, and putamen.

As with the regionally selective activation of frontal cortical DA systems by PCP, 5-HT utilization was significantly increased only in the monkey frontal cortex after PCP administration (Fig. 5). Significant increases in 5-HT metabolism were evident in the

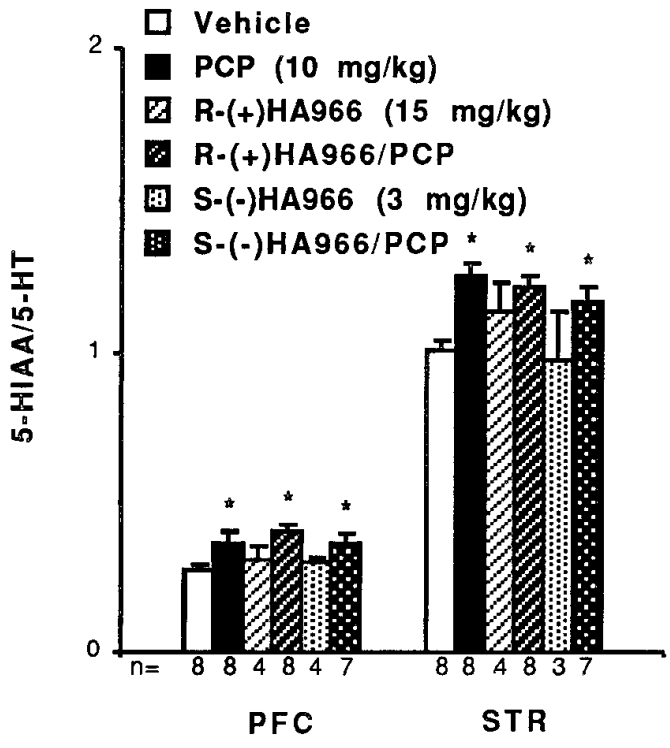

Figure 3. 5-HT utilization is increased in rat PFC and STR after PCP administration. Neither enantiomer of HA966 blocks these effects in either area. Results are expressed as mean \pm SEM. *Significantly increased relative to vehicle: $p<0.05$.

dorsolateral PFC $(T=-2.47 ; \mathrm{df}=8 ; p=0.039)$, prelimbic cortex $(T=-3.30 ; \mathrm{df}=3 ; p=0.046)$, and concentrations in $\mathrm{ng} / \mathrm{mg}$ protein \pm SEM.anterior cingulate $(T=-4.8$; df $=3 ; p=0.017)$. Interestingly, no significant increases in 5-HT utilization in the NAc, caudate, or putamen were observed after PCP administration.

\section{R-(+)- and S-(-)HA966 ameliorate PCP-stimulated increases in DA turnover in rat brain}

Neither enantiomer of HA966 caused any significant changes in basal concentrations of DA (Table 1) or DA utilization (Fig. 2) in any brain area studied, either alone or in combination with PCP, indicating that changes in DA turnover are dependent on metabolite concentrations. Hence, the isomers of HA966, at the doses studied presently, are without apparent effect on basal function of DA systems in rat brain.

Both R-(+)- and S-(-)HA966 partially ameliorated the stimulatory effects of PCP on DA utilization in the PFC (Fig. 2). R- $(+)$ HA966 caused a small but significant attenuation of PCP's effects in the PFC $(T=2.38$; df $=15 ; p=0.032)$, whereas S- $(-)$ HA966 produced a greater blockade of the PCP effect in the same area $(T=3.04 ; \mathrm{df}=13 ; p=0.010)$. In contrast, neither enantiomer had a significant effect on PCP-induced increases in DA turnover in the NAc (Fig. 2). Likewise, consistent with HA966 having selective effects on DA systems in rat brain, neither enanTable 2. Absolute dopamine levels are unaltered in monkey brain after
PCP or HA966

\begin{tabular}{lllll} 
& dlPFC & mPFC & lOrb & pLimb \\
\hline Saline & $0.26 \pm 0.07$ & $0.65 \pm 0.22$ & $1.75 \pm 0.13$ & $0.71 \pm 0.15$ \\
PCP & $0.25 \pm 0.02$ & $0.65 \pm 0.09$ & $1.66 \pm 0.58$ & $0.71 \pm 0.13$ \\
S- $(-) H A / P C P$ & $0.43 \pm 0.02$ & $0.92 \pm 0.11$ & $1.34 \pm 0.37$ & $0.88 \pm 0.05$
\end{tabular}

Whereas PCP increased DA turnover in the dIPFC, mPFC, lOrb, and pLimb of the monkey brain, it had no significant effect either alone, or in combination with S-(-)HA966, on DA concentrations, indicating that the effects are driven by changes in HVA levels. Results are expressed as mean DA concentrations in $\mathrm{ng} / \mathrm{mg}$ protein \pm SEM. 


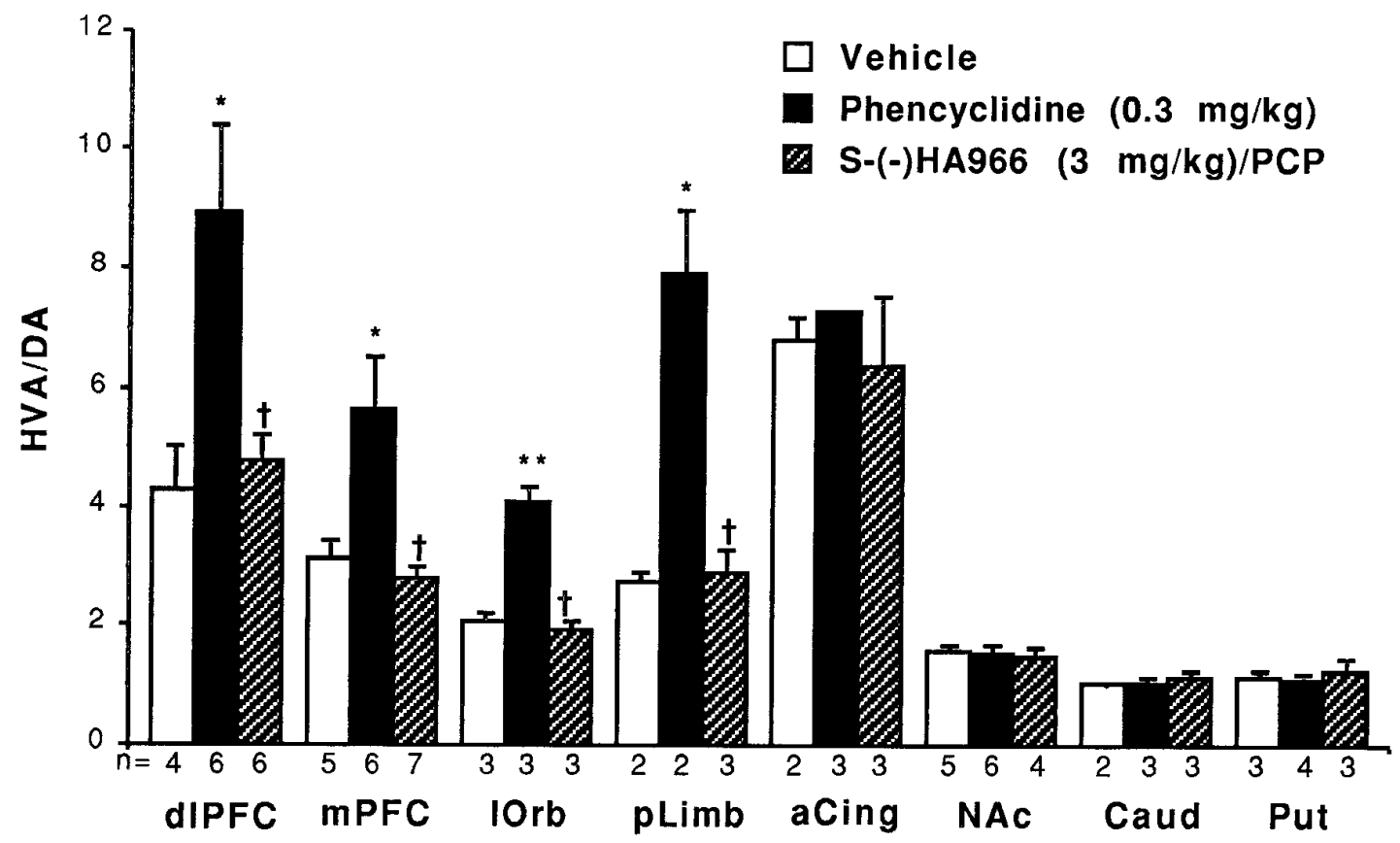

Figure 4. Phencyclidine increases DA turnover in monkey dorsolateral PFC (dlPFC), medial PFC ( $m P F C)$, lateral orbital cortex (lOrb), and prelimbic cortex ( pLimb), but not anterior cingulate (aCing), nucleus accumbens (NAc), caudate (Caud), or putamen (Put). The effect of PCP on frontal cortical DA metabolism is prevented by S- $(-)$ HA966. Results are expressed as mean \pm SEM. *Significantly increased relative to vehicle: $p<0.05$; ** significantly increased relative to vehicle: $p<0.01$; ${ }^{\dagger}$ significantly reduced relative to PCP: $p<0.05$.

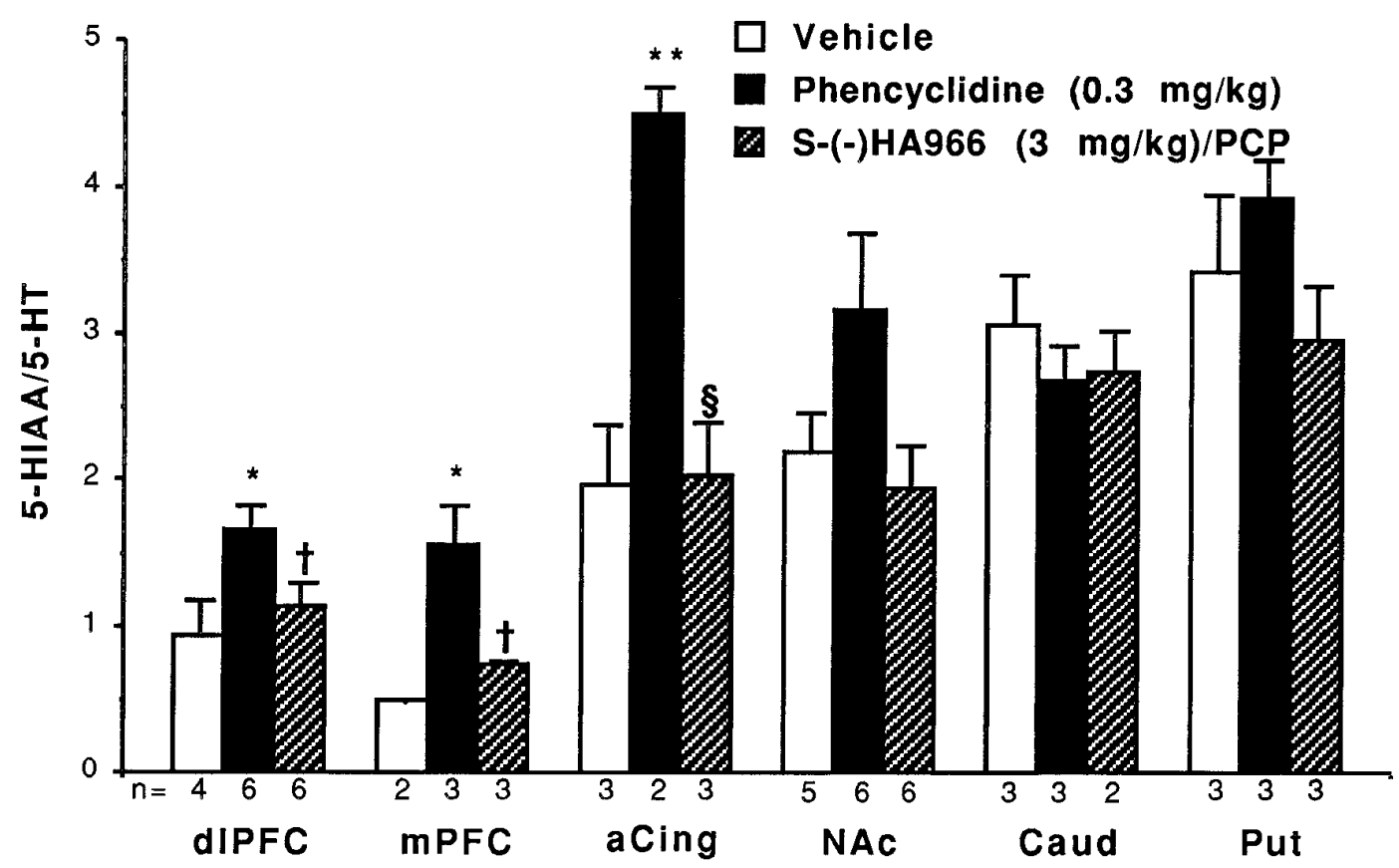

Figure 5. Phencyclidine selectively activates 5-HT metabolism in monkey frontal cortex, and this effect is blocked by S- $(-)$ HA966 pretreatment. Results are expressed as mean \pm SEM. *Significantly increased relative to vehicle: $p<0.05$; ${ }^{\dagger}$ significantly reduced relative to PCP: $p<0.05 ;{ }^{\S}$ significantly reduced relative to PCP: $p<0.01$.

tiomer significantly reversed the effect of PCP on 5-HT utilization in the rat PFC or STR (Fig. 3).

\section{PCP-induced activation of DA utilization in primate} brain is blocked by S-(-)HA966

Results with S- $(-)$ HA966 pretreatment in the primate parallel those obtained in the rodent. Increases in DA metabolism in the frontal cortex after PCP administration were completely blocked by pretreatment with S-(-)HA966 (Fig. 4). This effect was apparent in the dorsolateral prefrontal $(T=2.64, \mathrm{df}=10 ; p=0.025)$, medial prefrontal $(T=3.45 ; \mathrm{df}=11 ; p=0.005)$; lateral orbital $(T=6.93 ; \mathrm{df}=4 ; p=0.002)$, and prelimbic cortices $(T=5.25$; $\mathrm{df}=3 ; p=0.014)$. The effect of S- $(-)$ HA966 on DA turnover was 
dependent on changes in HVA concentrations, because no significant effect of cotreatment with S- $(-)$ HA966 and PCP on DA concentrations was observed (Table 2$)$.

Unlike its effect in the rat, S- $(-)$ HA966 was able to block increases in 5-HT turnover in the dorsolateral prefrontal $(T=$ 2.32 , $\mathrm{df}=10 ; p=0.042)$, prelimbic $(T=3.26$; $\mathrm{df}=4 ; p=0.031)$, and anterior cingulate cortices $(T=5.09 ; \mathrm{df}=3 ; p=0.015)$ induced by PCP in the primate (Fig. 5).

\section{DISCUSSION}

This study confirms previous reports that PCP activates DA metabolism in the PFC and NAc of rats (Deutch et al., 1987; Bowers and Morton, 1994). In addition, this report demonstrates that PCP has potent effects on monoamine transmission in the primate forebrain, exerting regionally selective effects on the DA and 5-HT innervations for the frontal cortex but sparing subcortical systems. These data suggest that the monoaminergic innervation of the monkey frontal cortex is regulated by a unique set of pharmacological influences.

Previous studies suggest that R- $(+)$ HA966 can alter the activating effects of PCP on PFC and NAc DA utilization in the rat (Bristow et al., 1993). In contrast, we find that at doses that have no effect on basal DA concentrations or turnover, R-(+)HA966 can only partially attenuate the PCP-induced increases in PFC DA. In contrast, S- $(-)$ HA966 does not significantly alter basal DA levels but more completely blocks the effects of PCP on PFC DA metabolism at an effective dose that is one fifth that of R- $(+)$ HA966. Neither enantiomer was found to block the increases in NAc DA turnover stimulated by PCP. These data agree with previous reports that R- $(+)$ HA966 can block increases in PFC, but not NAc, DA turnover induced by stress (Morrow et al., 1993; Goldstein et al., 1994).

In addition, S- $(-)$ HA966 can completely block the effects of PCP on DA and 5-HT turnover in the monkey frontal cortex. Interestingly, primates appear to be relatively resistant (or at least as sensitive as rodents) to the sedative effects of S- $(-)$ HA966 on a milligrams per kilograms basis. In a pilot behavioral study, a dose of $3 \mathrm{mg} / \mathrm{kg}$, i.m., was the highest dose that did not produce significant sedation in the monkey. We have observed previously that $3 \mathrm{mg} / \mathrm{kg}$, i.p., is the threshold for producing sedation in the rat. This low ratio of effective doses for rodents to primates is unusual but similar to that observed for $\gamma$-hydroxybutyrate (our unpublished observations).

\section{Selective effects of HA966 on DA systems in rodent, but not primate, brain}

The results of the current experiment suggest that the isomers of HA966 selectively modulate the activity of the rodent mesotelencephalic DA systems, because HA966 was unable to block the stimulatory effects of PCP on 5-HT turnover. This is supported additionally by reports that HA966 is unable to prevent the increases in 5-HT turnover induced by conditioned fear (Goldstein et al., 1994) or norepinephrine turnover induced by $\Delta 9$ tetrahydrocannabinol (Jentsch et al., 1997). Thus, it appears that in the rat, HA966 exerts regionally and neurochemically selective effects on stimulated states of frontal cortical DA turnover.

The effects of S- $(-)$ HA966 on DA and 5-HT turnover in the primate brain appear less selective for DA neurons, because we observed significant attenuation of PCP-induced increases in 5-HT turnover in the monkey brain. The substrate of this difference between rodents and primates is not clear; however, it may point to differences in the receptor-level regulation of brainstem monoaminergic neurons in the two species.

\section{PCP and HA966 alter the electrophysiology of midbrain DA neurons}

The effects of PCP on PFC and NAc DA turnover and release may be directly related to the increases in midbrain DA neuron burst firing elicited by PCP. DA neurons in areas A9 (substantia nigra pars compacta) and A10 [ventral tegmental area (VTA)] of the ventral mesencephalon perform in two alternate modes: tonic firing or burst firing (Grace and Bunney, 1984a,b). Population burst firing has been associated with increased DA release in terminal fields relative to tonic firing mode (Gonon, 1988; Bean and Roth, 1991). Therefore, PCP's ability to increase burst firing in subsets of A10 DA neurons (Raja and Guyenet, 1980; Freedman and Bunney, 1984; French, 1994) may be directly related to increased DA turnover and release in the terminal fields of the mesocorticolimbic DA systems after PCP administration.

R-(+)HA966, a glycine site/NMDA antagonist, reduces spontaneous burst firing in A10 DA neurons (McMillen et al., 1992). VTA DA neurons are regulated by a tonic, excitatory NMDAergic mechanism; local application of NMDA, but not kainate or quisqualate, to the VTA induces increased burst firing in DA neurons, whereas application of AP-5, but not CNQX, reduces spontaneous burst firing in the same neurons (Chergui et al., 1993). In addition, the excitatory amino acid antagonist kynurenate, which acts as an antagonist of the NMDA glycine modulatory site, prevents burst firing in midbrain DA neurons (Grenhoff et al., 1988; Wu et al., 1994). The competitive NMDA antagonist CPP prevents burst firing in VTA DA neurons induced by PCP (French, 1992). Taken together, this evidence suggests that the firing pattern of VTA DA neurons is preferentially modulated by NMDA-sensitive glutamate receptors and that, paradoxically, NMDA antagonism can prevent PCP-induced activation of DA neurons.

There is evidence that R-(+)HA966 is having its effect on NMDA receptors directly in the VTA. Recent biochemical studies have shown that intra-VTA infusions of R- $(+)$ HA966 can block the stimulatory effects of both restraint stress and the anxiogenic $\beta$-carboline FG7142 on PFC DA turnover (Morrow et al., 1993; Murphy et al., 1996c).

S-(-)HA966 also acts to regularize midbrain DA neuronal activity at low doses, while terminating impulse flow and increasing DA levels in terminal fields at high doses (Mocsary and Roth, 1994; Shepard et al., 1996; Grobaski et al., 1997). The pharmacological mechanism by which this action occurs is, unfortunately, unclear; however, it may be that S- $(-)$ HA966 acts through a $\mathrm{GABA}_{\mathrm{B}}$ or $\gamma$-hydroxybutyrate receptor mechanism. We have, however, observed that $\gamma$-hydroxybutyrate (via its lactone precursor) does not block the PCP-induced increases in rodent forebrain DA turnover (our unpublished observations), suggesting that S- $(-)$ HA966's $\gamma$ - hydroxybutyrate-like properties are not relevant in this paradigm. In addition, recent electrophysiological examinations suggest that a $\mathrm{GABA}_{\mathrm{B}}$ mechanism is likely not involved in S-(-)HA966's rate-suppressing effects on midbrain DA neurons in vivo (Grobaski et al., 1997). We await additional examinations of the pharmacological mechanism(s) of action of this potent regulator of DA function.

\section{Implications for pharmacological regulation of DA systems in primate brain}

Despite several decades of research into the pharmacological regulation of midbrain DA neurons in the rat brain, relatively little is known about the mechanisms controlling DA systems in the primate brain. The present study suggests that several findings 
in the rodent brain extend to the primate. First, it seems that the DAergic innervation of the frontal cortex in both species is subject to differential pharmacological regulation compared with that innervating such subcortical structures as the NAc, caudate, and putamen, because in the monkey, PCP only increased DA turnover in the frontal cortex. Second, S- $(-)$ HA966 is able to prevent PCP-induced increases in frontal cortical DA turnover in the primate brain as it does in the rat.

In addition to these similarities, there are differences between rodents and primates. Most notably is the fact that a significant increase in DA turnover in the rat NAc was observed after PCP administration, whereas there was no such effect in the primate NAc. In addition, S- $(-)$ HA966 was able to block the increase in 5-HT metabolism in primate brain, whereas it had no effect on the 5-HT increases induced by PCP in rodent brain. These differences and similarities urge future examinations of the biochemical pharmacology of the ascending monoamine systems in primate brain, because the implications for regulation of DA function in the human brain have relevance to numerous psychiatric and neurological disorders.

\section{Relevance to psychiatric disorders}

PCP and the PCP analog ketamine induce schizophreniform symptoms in normal humans and cause profound worsening of symptoms in schizophrenics (Luby et al., 1962; Javitt and Zukin, 1991; Krystal et al., 1994). At least a portion of these symptoms, the profound cognitive impairments exhibited after PCP or ketamine administration, may be related to a hyperdopaminergic state of the PFC. Increased DA transmission in the PFC induced by a pharmacological stressor, FG7142, impairs cognitive functioning in rats and primates (Murphy et al., 1996a), and a hyperdopaminergic substrate has also been observed to underlie the cognitive-impairing effects of $\Delta 9$ tetrahydrocannabinol (Jentsch et al., 1997) and ketamine and MK-801 (Verma and Moghaddam, 1996). As such, a hyperactive mesoPFC DA system may be the neurochemical correlate of the impaired working memory and negative symptoms of subjects given PCP, and HA966 may prove to be a pharmacological therapy for alleviating this dysfunction.

\section{REFERENCES}

Bean AJ, Roth RH (1991) Extracellular dopamine and neurotensin in rat prefrontal cortex in vivo: effects of median forebrain bundle stimulation frequency, pattern and dopamine autoreceptors. J Neurosci 11:2694-2702.

Bowers MB, Hoffman FJ (1989) Effects of diazepam on regional brain homovanillic acid following phencyclidine or $\Delta 9$-tetrahydrocannabinol. Biochem Pharmacol 38:2385-2387.

Bowers MB, Morton JB (1992) Diazepam antagonizes effects on dopamine metabolism produced by PCP receptor agonists. Prog Neuropsychopharmacol Biol Psychiatry 16:211-215.

Bowers MB, Morton JB (1994) Regional brain catecholamines and metabolites following THC, PCP and MK-801. Prog Neuropsychopharmacol Biol Psychiatry 18:961-964.

Bristow LJ, Hutson PH, Thorn L, Tricklebank MD (1993) The glycine/ NMDA receptor antagonist, R- $(+)$ HA966, blocks activation of the mesolimbic dopaminergic system induced by phencyclidine and dizocilpine (MK-801) in rodents. Br J Pharmacol 108:1156-1163.

Chergui K, Charlety PJ, Akaoka H, Saunier CF, Brunet JL, Buda M, Svensson TH, Chouvet G (1993) Tonic activation of NMDA receptors causes spontaneous burst discharge of rat midbrain dopamine neurons in vivo. Eur J Neurosci 5:137-144.

Deutch AY (1992) The regulation of subcortical dopamine systems by the prefrontal cortex: interactions of central dopamine systems and the pathogenesis of schizophrenia. J Neural Transm Suppl 36:61-89.

Deutch AY, Roth RH (1990) The determinants of stress-induced activation of the prefrontal cortical dopamine system. In: The prefrontal cortex: its structure, function and pathology (Vylings HBM, Van Eden CG, DeBruim JPC, Corner MA, Feenstra MGP, eds), pp 367-403. Amsterdam: Elsevier.

Deutch AY, Tam SY, Freeman AS, Bowers MB, Roth RH (1987) Mesolimbic and mesocortical dopamine activation induced by phencyclidine: contrasting pattern to striatal response. Eur J Pharmacol 134:257-264.

During MJ, Bean AJ, Roth RH (1987) Effects of CNS stimulants on the in vivo release of the colocalized transmitters, dopamine and neurotensin, from rat prefrontal cortex. Neurosci Lett 140:129-133.

Fadda F, Argiolas A, Melis MR, Tissari AH, Onali PL, Gessa GL (1978) Stress-induced increase in 3,4-dihydroxyphenylacetic acid (DOPAC) levels in the cerebral cortex and in N. accumbens: reversal by diazepam. Life Sci 23:2219-2224.

Freedman AS, Bunney BS (1984) The effects of phencyclidine and $N$-allyl-normetazocine on midbrain dopamine neuronal activity. Eur J Pharmacol 104:287-293.

French ED (1992) Competitive NMDA receptor antagonists attenuate phencyclidine-induced excitations of A10 dopamine neurons. Eur J Pharmacol 271:1-7.

French ED (1994) Phencyclidine and the midbrain dopamine system: electrophysiology and behavior. Neurotoxicol Teratol 16:355-362.

Goldstein LE, Rasmusson AM, Bunney BS, Roth RH (1994) The NMDA glycine site antagonist (+)HA966 selectively regulates conditioned stress-induced metabolic activation of the mesoprefrontal cortical dopamine but not serotonin systems: a behavioral, neuroendocrine, and neurochemical study in the rat. J Neurosci 14:4937-4950.

Gonon FG (1988) Nonlinear relationship between impulse flow and dopamine released by rat midbrain dopaminergic neurons as studied by in vivo electrochemistry. Neuroscience 24:19-28.

Grace AA (1991) Phasic versus tonic dopamine release and the modulation of dopamine system responsivity: a hypothesis for the etiology of schizophrenia. Neuroscience 41:1-24.

Grace AA, Bunney BS (1984a) The control of firing pattern in nigral dopamine neurons: single spike firing. J Neurosci 4:2866-2876.

Grace AA, Bunney BS (1984b) The control of firing pattern in nigral dopamine neurons: burst firing. J Neurosci 4:2877-2890.

Grenhoff J, Tung CS, Svensson TH (1988) The excitatory amino acid antagonist kynurenate induces pacemaker-like firing of dopamine neurons in the rat ventral tegmental area. Acta Physiol Scand 134:567-568.

Grobaski KC, Ping H, daSilva HMA, Bowery NG, Connelly ST, Shepard PD (1997) Responses of rat substantia nigra dopamine-containing neurons to S- $(-) \mathrm{HA} 966$ in vitro. Br J Pharmacol, in press.

Hondo H, Yonezawa Y, Nakahara T, Nakamura K, Hirano M, Uchimura H, Tashiro N (1994) Effect of phencyclidine on dopamine release in the rat prefrontal cortex: an in vivo microdialysis study. Brain Res 633:337-342.

Horger BA, Roth RH (1995) Stress and central amino acid systems. In: Neurobiological and clinical consequences of stress: from normal adaptation to PTSD (Friedman MJ, Charney DS, Deutch AY, eds), pp 61-81. Philadelphia: Lippincott-Raven.

Horger BA, Elsworth JD, Roth RH (1996) Blockade of FG7142-induced increased dopamine utilization by the glycine/NMDA receptor antagonist (+)HA966. J Neurochem 66:1959-1962.

Ital T, Keskiner A, Kiremitci N, Holden JMC (1967) Effect of phencyclidine in chronic schizophrenics. Can Psychiatric Assoc J 12:209-212.

Javitt DC, Zukin SR (1991) Recent advances in the phencyclidine model of schizophrenia. Am J Psychiatry 148:1301-1308.

Jentsch JD, Andrusiak EA, Tran A, Bowers MB, Roth RH (1997) $\Delta 9$ tetrahydrocannabinol increases prefrontal cortical catecholaminergic turnover and impairs spatial working memory in the rat: selective blockade of dopaminergic effects with HA966. Neuropsychopharmacology, in press.

Kim HS, Iyengar S, Wood PL (1986) Opiate actions on mesocortical dopamine metabolism in the rat. Life Sci 39:2033-2036.

Krystal JH, Karper JP, Seibyl JP, Freeman AS, Delaney GK, Bremner JD, Heninger GR, Bowers MB, Charney DS (1994) Subanesthetic effects of the noncompetitive NMDA antagonist, ketamine, in humans: psychotomimetic, perceptual, cognitive and neuroendocrine responses. Arch Gen Psychiatry 51:199-214.

Lavielle S, Tassin JP, Thierry AM, Blanc G, Herve D, Bathelemy C, Glowinski J (1978) Blockade by benzodiazepines of the selective high increase in dopamine turnover induced by stress in mesocortical dopaminergic neurons of the rat. Brain Res 168:585-594. 
Lowry OH, Rosebrough NJ, Farr AL, Randall RJ (1951) Protein measurement with the folin phenol reagent. J Biol Chem 193:265-275.

Luby ED, Cohen BD, Rosenbaum G, Gottlieb JS, Kelley R (1959) Study of a new schizophrenomimetic drug-sernyl. Arch Neurol Psychiatry $81: 363-369$

Luby ED, Gottlieb JS, Cohen BD, Rosenbaum G, Domino EF (1962) Model psychoses and schizophrenia. Am J Psychiatry 119:61-67.

McMillen BA, Williams HL, Lehmann H, Shepard PD (1992) On central muscle relaxants, strychnine-insensitive glycine receptors and two old drugs: zoxazolamine and HA966. J Neural Transm Gen Sec 89:11-25.

Mocsary Z, Roth RH (1994) Effects of HA966 and its enantiomers on dopamine neurotransmission in the striatum and the nucleus accumbens. Soc Neurosci Abstr 20:284.

Morrow BA, Clark WA, Roth RH (1993) Stress activation of mesocorticolimbic dopamine neurons: effects of a glycine/NMDA receptor antagonist. Eur J Pharmacol 238:255-262.

Morrow BA, Lee EJK, Elsworth JD, Nye H, Roth RH (1995) $S$-(-)HA966, a $\gamma$-hydroxybutyrate-like agonist, blocks behavioral and mesoaccumbal, in addition to, mesocortical dopaminergic stress activation. Soc Neurosci Abstr 21:852.

Murphy BL, Arnsten AFT, Goldman-Rakic PS, Roth RH (1996a) Increased dopamine turnover in the prefrontal cortex impairs spatial working memory performance in rats and monkeys. Proc Natl Acad Sci USA 93:1325-1329.

Murphy BL, Arnsten AFT, Jentsch JD, Roth RH (1996b) (+)HA966 and clonidine block FG7142-induced increases in prefrontal cortical dopamine turnover and prevent stress-induced impairments in spatial working memory in rats and monkeys. Soc Neurosci Abstr 22:161.

Murphy BL, Arnsten AFT, Jentsch JD, Roth RH (1996c) Dopamine and spatial working memory: pharmacological modulation of FG7142induced impairment. J Neurosci 16:7768-7775.
Raja SN, Guyenet PG (1980) Effects of phencyclidine on the spontaneous activity of monoaminergic neurons. Eur J Pharmacol 63:229-233.

Reinhard JF, Bannon MJ, Roth RH (1982) Acceleration by stress of dopamine synthesis and metabolism in prefrontal cortex: antagonism by diazepam. Naunyn Schmiedebergs Arch Pharmacol 318:374-377.

Robbins TW (1990) The case for frontostriatal dysfunction in schizophrenia. Schizophr Bull 16:391-402.

Roth RH, Elsworth JD (1995) Biochemical pharmacology of midbrain dopamine neurons. In: Psychopharmacology, the fourth generation of progress (Bloom FE, Kupfer DJ, eds), pp 227-243. New York: Raven.

Shepard PD, Connelly ST, Lehmann H, Grobaski KC (1996) Effects of the enantiomers of $( \pm)$ HA966 on dopamine neurons: an electrophysiological study of a chiral molecule. Eur J Pharmacol 285:79-88.

Singh L, Donald AE, Foster AC, Hutson PH, Iversen LL, Iversen SD, Kemp JA, Leeson PD, Marshall GR, Oles RJ, Priestley T, Thorn L, Tricklebank MD, Vass CA, Williams BA (1990) Enantiomers of HA966 (3-amino-1-hydroxypyrrolid-2-one) exhibit distinct central nervous system effects: $(+)$-HA966 is a selective glycine/ $N$-methyl-Daspartate receptor antagonist, but (-)-HA966 is a potent $\gamma$-butyrolactone-like sedative. Proc Natl Acad Sci USA 87:347-351.

Sorg BA, Kalivas PW (1993) Effect of cocaine and footshock stress on extracellular dopamine levels in the medial prefrontal cortex. Neuroscience 53:695-703.

Thierry AM, Tassin JP, Blanc G, Glowinski J (1976) Selective activation of the mesocortical DA system by stress. Nature 263:242-244.

Verma A, Moghaddam B (1996) NMDA receptor antagonists impair prefrontal cortical function as assessed via spatial delayed alternation performance in rats: modulation by dopamine. J Neurosci 16:373-379.

Wu HQ, Schwarcz R, Shepard PD (1994) Excitatory amino acid-induced excitation of dopamine-containing neurons in the rat substantia nigra: modulation by kynurenic acid. Synapse 16:219-230. 